\title{
EDUCAÇÃO E FARMÁCIA: QUESTÕES DE FUNDAMENTOS PARA A FORMAÇÃO PRÁTICA E A INTERDISCIPLINARIDADE
}

\author{
EDUCATION AND PHARMACY: FOUNDATIONS ISSUES FOR PRACTICAL \\ TRAINING AND INTERDISCIPLINARITY \\ Marcelo José de Souza e Silva ${ }^{1}$ \\ Adriano Jorge Torres Lopes ${ }^{2}$
}

RESUMO

Nesse trabalho se propõe um diálogo crítico com autores que têm trabalhado o tema educação farmacêutica recentemente, tendo como base uma análise sobre os fundamentos filosóficocientíficos das Diretrizes Curriculares Nacionais para os cursos de Farmácia. O intuito é sustentar uma posterior intervenção educacional direcionada para a interdisciplinaridade e a prática voltada para o Sistema Único de Saúde. Além disso, realizou-se uma análise sobre concepções de métodos e metodologias. A análise foi realizada através de uma leitura crítica dos autores, assim como de revisão de literatura sobre o assunto, calcada na materialidade histórico-dialética do ser social. Observou-se como resultado a necessidade de os estudos em educação farmacêutica analisados voltarem a sua atenção para as questões de fundamentos filosófico-científicas, pois são estas as bases para as teorias educacionais e diretrizes curriculares que retroalimentam a formação de farmacêuticos.

PALAVRAS-CHAVE: Educação farmacêutica. Diretrizes Curriculares Nacionais. Interdisciplinaridade.

\begin{abstract}
A critical dialogue was proposed here with authors who have worked on pharmaceutical education theme recently, based on an analysis of the philosophical and scientific foundations of the National Curriculum Guidelines for Pharmacy courses. The aim is to support a further educational intervention directed toward interdisciplinary and focused practice for the Sistema Único de Saúde. In addition, there was an analysis of concepts methods and methodologies. Analysis was performed through a critical reading of the authors, as well as a review of literature on the subject, based on the historical and dialectic materiality of the social being. It was observed as a result the need for studies in pharmaceutical education analyzed to return their attention to the issues of philosophical and scientific foundations, as these are the basis for the educational theories and curriculum guidelines that feedback the formation of Pharmacists.
\end{abstract}

KEYWORDS: Pharmaceutical education. National Curriculum Guidelines. Interdisciplinarity.

\footnotetext{
${ }^{1}$ Possui graduação em Farmácia pela Universidade Federal do Paraná (2011), mestrado em Educação pela Universidade Federal do Paraná (2013) e doutorado em Ciências (Medicina Preventiva) pela Universidade de São Paulo (2017). Tem experiência na área de Saúde Coletiva, com ênfase na relação entre Trabalho e Educação na área da Saúde e nas contribuições provenientes das Ciências Sociais para a Saúde.

${ }^{2}$ Possui graduação em Farmácia, com habilitação em Bioquímica, pela Universidade Federal do Maranhão (2009). Especialização em Docência e Pesquisa no Ensino Superior pela Faculdade São Luís (2011). Mestrado em Educação Brasileira pela Universidade Federal do Ceará (2012); Linha de Pesquisa Marxismo, Educação e Luta de Classes; Eixo Temático Ontologia Marxiana e Educação. Graduação em Pedagogia Licenciatura Plena, pela Universidade Estadual Vale do Acaraú (2017). Doutorado em Educação pela Universidade Estadual do Ceará (em andamento); Linha de Pesquisa Formação, Didática e Trabalho Docente; Núcleo Temático Marxismo e Formação do Educador.
} 


\section{INTRODUÇÃO}

A publicação dos artigos $O$ ensino de farmácia no sul do Brasil: preparando farmacêuticos para o Sistema Único de Saúde? (MONTEGUTI; DIEHL, 2016) e Interdisciplinaridade e formação na área de farmácia (Sousa e Bastos, 2016) nos mostra que as ciências farmacêuticas ainda vivem um momento dinâmico, em que reflete sobre si mesma, seu papel na sociedade, a formação das novas gerações e como fazê-lo em uma perspectiva que valorize o Sistema Único de Saúde (SUS).

Monteguti e Diehl (2016), com a sua pesquisa, buscaram analisar a apropriação das Diretrizes Curriculares Nacionais (DCN) pelos cursos de graduação em Farmácia do sul do Brasil, visando à formação direcionada à assistência farmacêutica no SUS; e avaliar a participação docente e discente de Instituições de Ensino Superior (IES) de Santa Catarina nas práticas de aproximação entre ensino e realidade de atuação no SUS, chegando à conclusão da necessidade de se repensar criticamente as DCN e de que forma vêm sendo implementadas pelos cursos de Farmácia.

Sousa e Bastos (2016) buscaram desvelar a compreensão de coordenadores de cursos de graduação em Farmácia da região Centro-Oeste do Brasil sobre a interdisciplinaridade na formação do farmacêutico. Os pesquisadores chegaram a alguns resultados referentes à necessidade de compreender melhor como a interdisciplinaridade dialoga com o currículo de Farmácia e à superação de obstáculos técnicos e políticos que impedem a prática interdisciplinar efetiva na formação dos farmacêuticos, entre eles a falta de capacitação docente e as disputas de poder entre áreas.

Entretanto, apesar de felizes com a publicação dos artigos, percebemos que ambos, cada um em sua especificidade, possuem questões que merecem ser apontadas criticamente, mostrando que a dinâmica das ciências farmacêuticas se mostra também na pluralidade em que é analisada. Nosso objetivo é realizar uma análise crítica dos fundamentos das DCN para os cursos de farmácia - um primeiro passo necessário para a posterior análise crítica dos objetivos propostos pelas diretrizes, como a necessidade de uma formação interdisciplinar e que a formação seja voltada para o trabalho no SUS.

\section{MÉTODO, METODOLOGIAS E FUNDAMENTOS DA PESQUISA}

Não seria fortuito afirmarmos que há um problema generalizado quando se trata dos termos método e metodologia nas análises científicas. Basta elencarmos uma curta, mas variada, lista de referências que abordam os dois termos em vias, ora completamente distintas, 
ora próximas, ora inteiramente idênticas, e ora mescladas entre si, tais como Guba e Lincoln (1994); Ferreira, Calvoso e Gonzales (2002); Brannen (2005); Sautu, Boniolo e Dalle (2005); Alveson e Sköldberg (2009); Ruto-Korin e Lubbe (2010); Denzin (2010); e Sampieri, Callado e Lucio (2013).

O problema de método e de metodologia tem um duplo caráter: primeiro, referente à própria compreensão dos termos; e segundo, concernente aos próprios fundamentos da investigação que desembocam em determinado método e dada metodologia. Sobre o primeiro caráter, tem-se que a falta de clareza sobre o que é método e metodologia resulta no uso indiscriminado dos termos. Um método de pesquisa pode ter a abrangência de conter inúmeras metodologias, assim como as mesmas metodologias podem ser utilizadas em métodos diferentes.

Vejamos, então, em linhas breves, cada termo mais especificamente.

É preciso entender método como uma forma abrangente e sistemática de se chegar ao conhecimento de algo. Por conseguinte, para se alcançar determinado conhecimento, tem-se dois pontos de partida: o gnosiológico ou o ontológico. Ao fim e ao cabo, ambos se referem à relação sujeito-objeto no processo de apreensão do conhecimento. O ponto de partida gnosiológico gira em torno do sujeito, que organiza e constrói o conhecimento, tendo a primazia da subjetividade como polo regente da referida relação. E o ponto de partida ontológico gravita ao redor do objeto, reconhecendo a objetividade do ser como primazia na apropriação da coisa (do ser, do ente), para constatar e traduzir o movimento do real. O posicionamento gnosiológico, por exemplo, decide, a priori, antes mesmo de se começar a investigação, quais as metodologias, procedimentos e demais etapas da pesquisa, satisfazendo, assim, o voluntarismo da sua própria razão (pendendo sempre para a subjetividade na relação sujeitoobjeto), organizando e construindo o conhecimento. Não estamos aqui fazendo alusão contrária aos projetos de pesquisa e elaboração de um plano investigativo. Mencionamos tão somente nossa crítica ao se escolher, a priori, elementos que deveriam ser decididos no decorrer da investigação e ao longo do processo de aproximação ao objeto, no qual o próprio objeto (mediado pela razão) deverá indicar quais instrumentos analíticos são mais apropriados para a sua apreensão.

Em contrapartida, do ângulo ontológico, surge a postura de ir diretamente ao objeto e traduzi-lo na forma de conhecimento, utilizando a razão (a subjetividade) para tanto. Para o posicionamento ontológico importa aquilo que o objeto é e não o que se pensa sobre ele. Por isso, a primazia é da objetividade do ser e não da subjetividade do pesquisador. A postura diante 
do conhecer é direcionada pela forma como o sujeito cognoscente desenvolve a sua relação com o objeto.

No interior de cada método, há uma vastidão de metodologias, as quais utilizam determinados instrumentos analíticos (intelectuais ou físicos), abordagens, procedimentos, entre outros, para se apropriar do conhecimento de algo. Ilustrando exemplos de metodologias, temos: a padronização de soluções químicas, entrevista, observação participativa, pesquisa bibliográfica, questionário, pesquisa documental e assim por diante.

As diversas metodologias estão inseridas em dois grandes pontos de partida que abarcam diferentes visões de mundo e, consequentemente, diversas conduções de pesquisas filosóficas e científicas. Pensemos na diferença qualitativa que se tem entre imaginar que o Sol gira em torno da Terra, sendo essa o centro do Universo; e se constatar que a Terra gravita ao redor do Sol, sendo aquela apenas mais um planeta e essa mais uma estrela na imensidão do Universo. Ou ainda, pensemos a distância qualitativa entre admitir (subjetivamente / ideologicamente) que não existe a categoria classes sociais no modo de produção capitalista contemporâneo; e constatar a sua existência com base na realidade do movimento do real, na objetividade do ser (social). Reconhecemos que a primeira ilustração é muito mais simples de se constatar hoje, justamente porque o segundo exemplo pode ser analisado do ponto de partida gnosiológico, acentuadamente subjetivo. Ao passo que não há espaço para dúvidas no sujeito em afirmar: a Terra gira em torno do Sol, sendo esta uma constatação ontológica, com primazia na objetividade do ser (com base nos conhecimentos sobre a Terra, o Sol, a gravidade etc.). Nesse caso, a subjetividade surge para traduzir o real, aquilo que o objeto é, e não para se sobressair como primazia, organizando e construindo o conhecimento, dando liberdade para o sujeito expressar a sua visão de mundo e relegar a segundo plano a objetividade.

Temos total clareza que, dadas as limitações do espaço de um artigo, a síntese aqui exposta tem caracteres muito lacunares, que poderão ser preenchidos qualitativamente através de nossas referências sugeridas. Todavia, acreditamos que cumprimos a tarefa de incitar a reflexão para tais problemas que são dados, no grande montante da pesquisa científica contemporânea, como pontos passivos que não são pautas de discussões.

A partir dessas observações iniciais, estamos posicionados entre aquelas pesquisas que possuem como método uma posição ontológica, calcada na materialidade históricodialética do ser social, que buscam entender o objeto enquanto o que ele é, e não simplesmente o que ele, à primeira vista, parece ser. Isso significa que a partir do exposto por Sousa e Bastos (2016) e Monteguti e Diehl (2016), realizaremos uma leitura ontológica da educação 
farmacêutica e, consequentemente, das Diretrizes Curriculares Nacionais para os cursos de Farmácia (DCNF) de forma a enquadrar ambas em um momento histórico determinado, que explica seus fundamentos, possibilitando, além de um entendimento aprofundado, uma autêntica crítica que possibilite a sua qualitativa superação.

\section{AS BASES HISTÓRICAS DO SURGIMENTO DAS DIRETRIZES CURRICULARES NACIONAIS PARA OS CURSOS DE FARMÁCIA}

Monteguti e Diehl (2016) retratam bem a movimentação histórica de profissionais, professores, estudantes e instituições de farmácia entre as décadas de 1960 e 1990 de crítica ao Currículo Mínimo e com o intuito de modificações na formação do profissional farmacêutico, que culminou com as Diretrizes Curriculares Nacionais. Entretanto, essa mudança não ocorreu de forma isolada na área de farmácia, mas se deu em um contexto de reforma geral do ensino superior no Brasil no início da década de 2000, que tem como base histórica a crise do início da década de 1970.

De acordo com Marx (2013), o capitalismo é um modo de produção dependente da produção de valor que se tornará capital, que necessita constantemente ser valorizado e revalorizado. O trabalho (sob o capitalismo) cria valor e, através do trabalho assalariado, é possível extrair também um mais-valor dos trabalhadores, que se tornará lucro e será valorizado, tornando-se o próprio capital; entretanto, com o passar do tempo e desenvolvimento dos meios de produção, passa a ser empregado uma menor quantidade de trabalhadores e uma maior de maquinaria. Isso faz com que o montante relativo extraído do conjunto de trabalhadores seja menor, apesar do montante absoluto de mais-valor explorado poder ser maior. Essa tendência leva a uma diminuição na obtenção de lucro obtido, pela diminuição do valor das mercadorias. Com o aumento da produtividade - aumento da quantidade de mercadorias produzidas em um mesmo período - se diminui o custo repassado para cada produto, dilui-se o valor do capital constante utilizado em um maior número de mercadorias, diminui-se o lucro obtido com cada mercadoria. Novamente, é possível que o montante absoluto de lucro aumente, entretanto, a taxa de lucro cai relativamente em cada produto.

O aumento da produtividade e a diminuição relativa da taxa de lucro levam a uma superprodução, diminuindo ainda mais a taxa média de lucro. Quando a taxa média de lucro chega em um patamar em que não é mais possível revalorizar o capital, ocorrem as chamadas

crises. E para sair das crises, é preciso destruir valor, tanto simbolicamente, quanto concretamente, através da destruição de mercadorias. Também é necessário simplificar o 
trabalho, diminuindo a quantidade paga ao trabalhador, possibilitando o aumento da exploração de mais-valor.

A crise chamada de Grande Depressão de 1929 levou a uma grande destruição de valor, principalmente com a Segunda Guerra Mundial. Essa destruição permitiu que o capitalismo vivesse o que Hobsbawm (2011) chamou de a Era de Ouro ou os Trinta Anos Gloriosos, em que as taxas de lucro médias chegaram a patamares nunca antes alcançados pela humanidade. Entretanto, segundo Kliman (2012), a queda tendencial da taxa de lucro continuou mesmo nesse período, mas de forma imperceptível, pois sempre que a taxa de lucro média caia, ainda se encontrava acima do nível necessário para a reprodução do capital.

No entanto, no início da década de 1970 essa queda se fez sentir, o que levou à grande crise de 1973, sendo necessário novamente destruição de capital. Entretanto, como os governos não desejavam a radicalização do movimento dos trabalhadores que aconteceu em outros momentos e como ainda se vivia uma Guerra Fria, ocorreu uma intervenção com políticas monetárias e fiscais com o intuito de prevenir uma destruição em massa de valor de capital. Segundo Kliman (2012, p. 3, tradução nossa):

\footnotetext{
Isso explica porque recessões subsequentes na economia não têm sido tão severas como da Depressão. Mas desde que muito menos valor de capital foi destruído durante a década de 1970 e início da década de 1980 do que foi destruído na década de 1930 e início da década de 1940, o declínio na taxa de lucro não foi revertido. E por não ter sido revertido, a rentabilidade se manteve em um nível muito baixo para sustentar um novo crescimento.
}

Para prevenir o que aconteceu na década de 1930, políticos usaram, com sucesso, financiamento e garantias de dívidas para retardar e desviar da destruição de capital. Como a destruição de capital é o principal fator que restaura a rentabilidade e, portanto, é o grande responsável pela próxima fase de crescimento, não houve um crescimento como o que ocorreu depois da Grande Depressão e da Segunda Guerra Mundial.

Em resposta a essa crise, ocorreram reformas dentro do capitalismo (sem, entretanto, mudar suas estruturas), com o neoliberalismo ganhando força como forma de gerenciamento do Estado; e o toyotismo surge como forma principal de reestruturação da produção e do trabalho (Antunes, 2009). De acordo com Antunes (2009, p. 36), "desemprego em dimensão estrutural, precarização do trabalho de modo ampliado e destruição da natureza em escala globalizada tornaram-se traços constitutivos dessa fase da reestruturação produtiva do capital". Na área farmacêutica, isso se deu principalmente pela precarização do trabalho e pela simplificação do processo de trabalho, transferindo para o maquinário grande parte do conhecimento elaborado, restando ao trabalhador a tarefa de operá-lo. A elaboração desse 
conhecimento se restringe ainda mais aos países capitalistas avançados. A simplificação do trabalho faz com que não seja mais necessário um profissional altamente qualificado, com uma formação aprofundada, com a transmissão dos conhecimentos histórico e socialmente produzidos pela humanidade.

Dessa forma, a reestruturação produtiva, através de mediações dentro das relações sociais de produção capitalistas, também incide sobre a educação escolar, uma vez que, juntamente com esse novo tipo de produção, também surge a necessidade de um trabalhador que se adeque melhor a essa nova produção. A necessidade desse novo trabalhador faz com que seja necessária também uma nova formação, voltada para essa nova organização do trabalho. Isso leva a órgãos internacionais, como UNESCO, UNICEF, UNDP e Banco Mundial, a elaborarem vários documentos que influenciaram as políticas de educação em nosso país, baseando-se na teoria do capital humano, na qual a educação é entendida como um dos principais determinantes na competição entre os países.

No Brasil, a década de 1990 consolida governos neoliberais e ocorre também uma reestruturação da produção, levando a adoção, com a promulgação da Lei de Diretrizes e Bases (LDB) da Educação em 1996, desse ideário da necessidade de uma nova formação, para um novo trabalhador. A LDB será a base para a reforma do ensino superior iniciada na década de 2000 com a promulgação de Diretrizes Curriculares Nacionais para os diversos cursos do ensino superior, cujo primeiro movimento ocorreu majoritariamente entre 2001 e 2004, mas continuando até hoje em dia. As diretrizes extinguiram os antigos Currículos Mínimos (currículos baseados no ensino tecnicista - um dos frutos da ditadura militar), flexibilizando ao máximo a estruturação pedagógica de cada universidade/faculdade do país, com o intento de flexibilizar e priorizar áreas do conhecimento na construção dos currículos de cada escola.

Para os cursos de graduação em Farmácia, as Diretrizes Curriculares Nacionais são promulgadas em 2002, de acordo com a LDB e com as recomendações da Organização PanAmericana de Saúde (OPAS/OMS) para o curso de Farmácia nas Américas (Breyner, 2006). A partir de sua publicação, todas as escolas de Farmácia do Brasil deveriam adequar seus currículos às novas diretrizes, acabando com as especialidades e formando o farmacêutico generalista a partir da teoria das competências e da educação ao longo da vida (Brasil, 2002) Em outubro de 2017, foram promulgadas as mais recentes Diretrizes Curriculares para os cursos de farmácia, com algumas mudanças mais significativas que a de 2002, como uma maior ênfase no cuidado em saúde, mantendo, entretanto, a base pedagógica que orienta os cursos intacta 
(Brasil, 2017) - a partir da teoria das competência e da educação continuada/permanente, teorias enquadradas no chamado ideário do aprender a aprender.

\section{FUNDAMENTAÇÕES FILOSÓFICO-CIENTÍFICAS DAS DIRETRIZES CURRICULARES PARA OS CURSOS DE FARMÁCIA}

Uma etapa importante e, infelizmente, não tão bem explorada nos processos investigativos sobre educação farmacêutica é referente aos fundamentos de determinada teoria, hipótese, argumentos ou mesmo tendências, ideários e perspectivas em geral. Sobre fundamentos, leia-se: gênese, origem e função, sempre buscando a aproximação maior possível das características mais essenciais de determinado fenômeno e/ou categoria analisados.

Fizemos, no tópico anterior, um resgate histórico situando em linhas gerais o momento econômico no Brasil e no mundo, que antecedeu a criação das DCNF, fazendo enlaces correspondentes entre a base político-econômica e os seus direcionamentos refletidos nas estruturas educacionais, sistematizadas nas LDB e, por extensão, às Diretrizes Curriculares Nacionais dos cursos de graduação no Brasil. Nesta seção, faremos o esforço em demonstrar, em síntese, a fundamentação filosófico-científica na qual se baseia a proposta oficial para a formação de farmacêuticos no Brasil. Partindo das próprias DCNF, fica nítida a sua expressa filiação à tendência pedagógica do aprender a aprender quando diz que o profissional deve estar em uma educação permanente, "os profissionais devem aprender a aprender" (BRASIL, 2002, art. $3^{\circ}$ ), mantido no artigo $4^{\circ}$ das diretrizes de 2017. Da mesma maneira, permaneceu a ênfase nas competências, conforme artigos $5^{\circ}, 6^{\circ}, 8^{\circ}, 12^{\circ}$ e $17^{\circ}$ das retrocitadas diretrizes (BRASIL, 2017).

A tendência pedagógica do aprender a aprender envolve um conjunto heterogêneo de ideários nas ciências da Educação que, apesar das particularidades que as diferem uma das outras, carregam elementos centrais em comum. Temos como exemplos de algumas dessas tendências mais conhecidas: Escola Nova, Pedagogia das Competências, Metodologias Ativas, Pedagogia do Professor Reflexivo, Multiculturalismo e Construtivismo.

A espinha dorsal que articula as tais tendências pedagógicas foi dissecada com muita qualidade por Duarte (2006), que elenca quatro posicionamentos valorativos contidos no lema aprender a aprender.

I) Coloca as aprendizagens adquiridas pelo indivíduo por si só, de forma autônoma e espontânea como mais importantes do que os conhecimentos transmitidos pelo intermédio de outros indivíduos (DUARTE, 2006). 
Nesse primeiro posicionamento, a postura de autonomia e espontaneidade no processo educativo é também compartilhada por nós como favorável. Convém discutir, todavia, o ressalto de que essa posição seria mais importante do que os conhecimentos transmitidos pelo intermédio de outros indivíduos, afeta diretamente a própria atividade docente e os estágios no processo de ensino-aprendizagem, pois a autonomia e espontaneidade são adquiridas após a aquisição de conhecimentos suficientes para tanto, transmitidos direta e intencionalmente de quem ensina para quem aprende. Segundo Saviani (2008, p. 13), educação é

o ato de produzir direta e intencionalmente, em cada indivíduo singular, a humanidade
que é produzida histórica e coletivamente pelo conjunto dos homens. Assim, o objeto
da educação diz respeito, de um lado, à identificação dos elementos culturais que
precisam ser assimilados pelos indivíduos da espécie humana para que eles se tornem
humanos e, de outro lado e concomitantemente, à descoberta das formas mais
adequadas para atingir esse objetivo.

Cabe perceber aqui que pôr ênfase hierarquicamente na aprendizagem autônoma e espontânea do educando como superior e mais desejável que a transmitida direta e intencionalmente por um educador pode acarretar a superestimação do aluno, colocando em segundo patamar a transmissão sistemática pelo professor. De nossa parte, concordamos que a educação formal deve proporcionar autonomia e espontaneidade na pesquisa e progressivo desenvolvimento intelectual, mas é preciso perceber o processo que desencadeia essa condição e que a transmissão direta e intencional das formas mais elevadas do conhecimento socialmente produzidos não é uma barreira para se chegar a esse estágio.

II) O segundo posicionamento valorativo assevera ser mais importante o aluno desenvolver uma metodologia própria de aquisição, elaboração, descoberta e construção de conhecimentos, do que aprender os conhecimentos que foram descobertos e elaborados por outras pessoas (DUARTE, 2006).

Esse segundo posicionamento é uma extensão do primeiro, supervalorizando a metodologia de conhecimento em detrimento do conhecimento como produto. Pode ser analisada como uma inversão entre o ponto de partida e o ponto de chegada. Jean Piaget, importante teórico muito utilizado pelo Construtivismo, ilustra bem esse posicionamento:

O problema da educação internacional é, portanto, essencialmente o de direcionar o adolescente não para soluções prontas, mas para um método que lhe permita construílas por conta própria (PIAGET apud DUARTE, 2006, pp. 35-36).

Ao invés de o ponto de partida ser aquilo que a humanidade já produziu (descobriu, traduziu da realidade) historicamente e incorporou como seu patrimônio cultural, retrocede-se 
a um patamar anterior, gastando tempo e energia para se direcionar ao estágio do qual poderia se ter iniciado e não chegado.

É compreensível que as DCNF se esforcem em distanciar a sua proposta educacional dos antigos Currículos Mínimos, vinculados ao tecnicismo do período da ditadura militar brasileira. Tecnicismo esse, criticado de forma justa por sua transmissão mecânica de conteúdos programáticos, sem permitir um espaço de reflexão durante as mediações entre o ponto de partida e o ponto de chegada do conhecimento. Dessa forma, as DCNF de 2002 expuseram no artigo 13 e ficou mantido no artigo 12 das DCNF de 2017 que os currículos dos cursos de graduação em Farmácia devem ter como estrutura:

contemplar a abordagem de temas observando o equilíbrio teórico-prático, desvinculado da visão tecnicista, permitindo na prática e no exercício das atividades a aprendizagem da arte de aprender (BRASIL, 2017, art. 12, grifos nossos).

Como já sabemos que se trata das tendências pedagógicas do aprender a aprender, então em contraposição à visão tecnicista, a arte de aprender deve ser entendida, dentre outras, como a criação de metodologias próprias para se chegar ao conhecimento. No intuito generalizado de se opor ao tecnicismo, o aprender a aprender tende a tratar toda transmissão de conhecimento como mecânica e, por consequência, indesejável também os produtos e resultados que dela podem vir. Saviani esclarece o equívoco do aprender a aprender ao refutar a postura da Escola Nova:

Tendo claro que é o fim a atingir que determina os métodos e processos de ensinoaprendizagem, compreende-se o equívoco da Escola Nova em relação ao problema da atividade e da criatividade. Com efeito, a crítica ao ensino tradicional era justa, na medida em que esse ensino perdeu de vista os fins, tornando mecânicos e vazios de sentido os conteúdos que transmitia. A partir daí, a Escola Nova tendeu a classificar toda transmissão de conteúdo como mecânico e todo mecanismo como anticriativo, assim como todo automatismo como negação da liberdade (SAVIANI, 2008, p. 18).

III) $\mathrm{O}$ terceiro posicionamento elabora que a própria atividade do discente deve mover o processo educacional, ou seja, a educação deve ser impulsionada pelos interesses e necessidades do estudante (DUARTE, 2006).

Esse posicionamento expõe com muita nitidez uma das categorias centrais que dá unidade às tendências pedagógicas do aprender a aprender: a centralidade no estudante. Esta postura tende a ignorar que o educando é um indivíduo síntese das relações sociais contraídas necessariamente pelas inúmeras mediações no sistema produtivo, que expressam uma visão de mundo a partir do ângulo de uma classe social, com suas ideologias, esboçando uma subjetividade característica a essa peculiaridade. Em outros termos, o estudante chega ao ambiente de educação formal com uma bagagem cotidiana repleta de preconceitos, 
generalizações apressadas, alienações diversas etc., ao passo que o processo filosóficocientífico de ensino-aprendizagem necessita do não-cotidiano - sistematizações não-naturais, não-espontâneas, reflexivas e críticas (Rossler, 2006) - para que, em outro estágio mais complexo, possa voltar ao cotidiano (agora enriquecido subjetivamente pelas objetivações nãocotidianas) para fazer análises qualitativamente superiores em relação à aproximação ao objeto do real.

A crítica supracitada se estende às DCNF, tanto as de 2002 no artigo $9^{\circ}$ como as de 2017 no artigo 12, as quais defendem abertamente este terceiro posicionamento valorativo:

O Curso de Graduação em Farmácia deve ter um projeto pedagógico, construído coletivamente, centrado no aluno como sujeito da aprendizagem e apoiado no professor como facilitador e mediador do processo ensino-aprendizagem. Este projeto pedagógico deverá buscar a formação integral e adequada do estudante através de uma articulação entre o ensino, a pesquisa e a extensão/assistência (BRASIL, 2017, art. 12, grifos nossos).

IV) Por fim, o quarto posicionamento valorativo do aprender a aprender trata de reduzir a educação à mera função de preparar o indivíduo, adaptando-o às exigências do mercado de trabalho (DUARTE, 2006).

A miopia gerencial e arrogante e a resistência à mudança, que paira em grande parte
no sistema produtivo, devem dar lugar à aprendizagem, ao conhecimento, ao pensar,
ao refletir e ao resolver novos desafios da atividade dinâmica que caracteriza a
economia global dos tempos modernos. [...] os empresários e os trabalhadores devem
cada vez mais investir no desenvolvimento do seu potencial de adaptabilidade e de
empregabilidade [...] O êxito do empresário e do trabalhador do século XXI terá muito
que ver com a maximização das suas competências cognitivas. Cada um produzirá
mais na razão direta de sua maior capacidade de aprender a aprender [...] A capacidade
de adaptação e de aprender a aprender e a reaprender, tão necessária para milhares de
trabalhadores que terão de ser reconvertidos em vez de despedidos, a flexibilidade e
modificabilidade para novos postos de trabalho vão surgir cada vez com mais
veemência. [...] e tais postos de trabalho terão que ser conquistados pelos
trabalhadores preparados e diferenciados em termos cognitivos (FONSECA apud
DUARTE, 2006, pp. 41-42).

A preocupação nas DCNF com a relação entre mercado e ensino nos apresenta uma faceta já esperada que, historicamente, é apropriada pela estrutura político-econômica, direcionando a educação e a pesquisa científica aos interesses privados do meio empresarial. Observemos que a própria nomenclatura vocabular nas DCNF incorpora os termos utilizados nas empresas e fábricas privadas, como: ter "liderança" e serem "empreendedores" (BRASIL, 2002, p. 2), ter "competências e habilidades" (Idem, ibidem), ter "flexibilidade" (Idem, p. 4), “empreendedorismo" (Idem, p. 2), "gerenciamento e execução de ações” (Idem, ibidem).

Apesar de estar registrado nas DCNF que "a formação do Farmacêutico deverá contemplar as necessidades sociais da saúde [...] com ênfase no Sistema Único de Saúde" 
(BRASIL, 2002, p. 3), o que não permanece nas Diretrizes de 2017, é preciso verificar como e qual é a concepção de serviço público abordada no processo de ensino-aprendizagem. Principalmente em se tratando das tão atuais, em voga, Parcerias Público-Privadas, que descaracterizam a gratuidade do serviço público e injetam a dinâmica de trabalho da lógica privado-empresarial através das terceirizações de serviços prestados.

O farmacêutico e professor Paulo Roberto Boff concedeu, em 2012, uma entrevista à revista Pharmácia Brasileira, comentando sobre as DCNF, na qual fez a seguinte crítica:

Não se pode conceber flexibilização apenas como uma janela para as facilidades oferecidas à instituição de ensino, para que esta planeje o seu curso voltado apenas para o mercado e o modelo econômico, transformando o farmacêutico exclusivamente em mão de obra de uma engrenagem, muitas vezes, desumana e perniciosa à sociedade.

O farmacêutico é um profissional da saúde que, além de ser uma excelência técnica, precisa ser dotado de uma grande capacidade crítica, de uma forte base humanística e universal, e inteirado das questões sociais (BOFF, 2011-2012, p. 53).

E arremata, expondo a íntima relação entre o mercado educacional no ensino de Farmácia e as DCNF:

A colega Silvana Nair Leite, professora do departamento de Ciências Farmacêuticas da UFSC (Universidade Federal de Santa Catarina) e que já realizou avaliação de cursos de Farmácia pelo INEP (Instituto Nacional de Estudos e Pesquisas Educacionais Anísio Teixeira), confidenciou-me que um dos efeitos das próprias Diretrizes é a permissividade de "nivelar por baixo".

Os cursos de Farmácia tradicionalmente eram caros, com muitos laboratórios, equipamentos, linhas de pesquisa etc., infraestrutura essencial para que se tenha um bom curso em funcionamento. Mas isso não aparece como exigência nas Diretrizes. Há uma forte subjetividade neste quesito. A exigência está pautada apenas em estágio no SUS, em clínica. A colega Silvana afirma que, por conta disso, as partes técnica, tecnológica e de P\&D (pesquisa e desenvolvimento) perderam força.

Diz ela: "Com isso, na prática, quase qualquer coisa pode ser enquadrada dentro das Diretrizes Curriculares e ser aprovada. Senti muito isso, fazendo avaliações para o INEP. É praticamente impossível dizer que o curso não tem condições físicas e materiais para oferecer um bom ensino de Farmácia". Isso pode ter sido estratégico para a ampliação do número de cursos e da situação que temos, agora (BOFF, 20112012, p. 55).

Em síntese, as Diretrizes Curriculares Nacionais para os cursos de graduação em Farmácia não fogem à lógica das DCN para os demais cursos do ensino superior brasileiro; a lógica de um ensino voltado para o mercado de trabalho, esse que, desde a revolução produtiva e ascensão do neoliberalismo, busca ao máximo a incorporação do conhecimento nas tecnologias, relegando ao trabalhador sua simples operação, como forma de barateamento da força de trabalho, com o intuito de aumento da taxa de lucro. Além disso, simplesmente operar a tecnologia (tornar o trabalhador um apêndice da máquina) leva a não ser necessário a 
transmissão dos conhecimentos elaborados pela humanidade, indo ao encontro do ideário do aprender a aprender que permeia as DCNF.

\section{A INTERDISCIPLINARIDADE COMO SOLUÇÃO PARA A FRAGMENTAÇÃO DO ENSINO}

Almeida Filho (2005, p. 33) considera a disciplinaridade a forma fragmentada de ensino proveniente da ciência moderna, "baseada na fragmentação do objeto e numa crescente especialização do sujeito científico", e Alvarenga, Sommermann e Alvarez (2005) argumentam que isso ocorre devido ao rompimento radical com a tradição do pensamento clássico e enciclopedista, descartando qualquer tentativa de universalidade do pensamento humano e contribuindo a dissociação entre ciências e humanidades. Para Sousa e Bastos (2016), o ensino de Farmácia ainda está baseado nesse modelo, a partir da visão reducionista do ensino e calcado nas especialidades. Todos os autores sugerem como solução para esses problemas a interdisciplinaridade que, segundo Sousa e Bastos (2016), é uma linha axiomática que integra diversas disciplinas, com uma noção de finalidade. A interdisciplinaridade, portanto, busca uma comunicação entre os domínios do saber, ou seja, busca as possíveis inter-relações entre as disciplinas próximas e distantes, a partir de práticas interdisciplinares, não negando o disciplinar (a disciplinaridade), mas relativizando-o, constituindo-se em um "saber que organiza diferentes saberes" (Alvarenga, Sommermann e Alvarez, 2005, p. 16) e que, principalmente, cria a relação entre a ciência moderna e o ensino de humanidades. E, sobretudo, "a interdisciplinaridade não se ensina nem se aprende, apenas vive-se" (Sousa e Bastos, 2016, p. 105).

Compreendemos os esforços dedicados por esse movimento na tentativa de acabar com a fragmentação do ensino, porém, acreditamos que a solução proposta não fornece meios reais para atingir o objetivo proposto. A proposta da interdisciplinaridade busca superar a disciplinaridade, mantendo, contudo, tanto as disciplinas quanto a base que leva a existirem disciplinas. Obtém-se como produto um novo ensino também fragmentado, mas que está baseado em disciplinas conversando com outras disciplinas (fragmentos conversando com fragmentos). Esse movimento busca uma superação a partir de uma solução equivocada, e que, apesar de ser aparentemente diferente daquilo que quer superar, no final, acaba no mesmo ponto, em um ensino disciplinar (que conversa entre si) que não supera a fragmentação da educação.

Isso ocorre, pois a interdisciplinaridade está baseada na - e somente nela - lógica formal, ou seja, está preocupada apenas em como se organiza o pensamento, em apenas 
entender como pensa o pensamento, e não como esse pensamento/conhecimento foi produzido e, principalmente, como, a partir dele, transformar a realidade. Segundo Ilyenkov (2010), a lógica formal é a lógica que estabelece os limites do conhecimento - limites os quais o conhecimento não pode ultrapassar, não importam as circunstâncias, ou quão elevado esteja o desenvolvimento das capacidades cognitivas de uma pessoa ou da humanidade, ou da técnica da pesquisa ou experimento científico.

A interdisciplinaridade, enquanto solução restrita ao campo da epistemologia ou teoria do conhecimento, está baseada em uma aceitação a priori de que o conhecimento humano é apenas um processo de ordenação, organização e sistematização dos fatos da experiência individual e não que o conhecimento humano é o conhecimento do mundo que existe fora e independentemente da consciência humana - apreendido por essa mesma consciência. Em outras palavras, para a epistemologia, qualquer área científica, seja ela a física ou a economia política, a matemática ou a história, não nos diz e não poderia dizer sobre como a matéria está no mundo externo, porque só descreve fatos que surgem dentro de nós mesmos, dos fenômenos psicofisiológicos que são percebidos, de forma ilusória, como a simples soma dos fatos externos. Qualquer conhecimento não é conhecimento do mundo ao redor do ser humano, mas somente um esquema da organização dos assuntos do conhecimento (Ilyenkov, 2010).

Assim, segundo Ilyenkov (2010), a lógica formal não possui uma relação imediata com o mundo real, mas somente com coisas já realizadas, com os fenômenos psíquicos da cultura humana. É, portanto, tarefa da lógica formal a análise das imagens já disponíveis na consciência, transformando-as em componentes mais simples, expressos em termos definidos e a posterior operação de síntese desses termos, pelas mesmas regras, com cada fato isolado da totalidade que compõe o conjunto ao qual pertence.

É dessa forma que vê o conhecimento a interdisciplinaridade, como diversos fatos isolados que precisam conversar, acreditando que essa é a solução para acabar com a fragmentação do ensino. Entretanto, como o conhecimento parte da realidade (Marx e Engels, 2009), um conhecimento fragmentado é reflexo de uma realidade fragmentada. Sob o modo de produção capitalista, a humanidade alcançou níveis de desenvolvimento nunca vistos antes em sua história; entretanto, contraditoriamente, o fez a partir de uma fragmentação da prática social e do sujeito, expressa na fragmentação do conhecimento sobre essa realidade material.

Por isso, acreditamos que a interdisciplinaridade é uma solução equivocada para combater a fragmentação do saber. Um dos motivos seria a pressuposição de "que a complexificação e a fragmentação são simplesmente resultados naturais do processo social, 
sendo a segunda uma consequência necessária da primeira" (TONET, 2013a, p. 729). Outro motivo é a análise do conhecimento prescindindo da análise da prática social, já que é dessa prática, dessa realidade objetiva, que se engendra o conhecimento. Dessa forma, a interdisciplinaridade "termina por atribuir ao conhecimento uma autonomia que ele de fato não tem, tratando, assim, a fragmentação do saber como um processo que se dá no interior do próprio saber" (TONET, 2013a, p. 729), buscando resgatar a totalidade perdida através da simples soma dos diversos fragmentos do saber - ou, em outras palavras, através da comunicação, da conversa entre esses diversos fragmentos. Partindo do pressuposto dessa autonomia do saber, a interdisciplinaridade não faz a crítica ao processo material de fragmentação, limitando-se a buscar a superação deste estado "pelas vias epistêmica, pedagógica ou comportamental" (TONET, 2013a, p. 729). Além disso, toma o padrão moderno de cientificidade (altamente especializado sem correspondência com a totalidade do conhecimento) como se fosse o único caminho para a produção do conhecimento científico (enquanto conhecimento que busca explicar a realidade objetiva), ignorando que essa fragmentação do conhecimento faz parte de um modo específico de se fazer ciência, e que esse modo foi originado da prática social do modo de produção capitalista. A ciência capitalista é reflexo do próprio capitalismo.

O ser humano, enquanto único animal cuja atividade é voltada a um fim, ao suprir suas necessidades, cria outras, que também precisam ser supridas (MARX E ENGELS, 2009). Como a partir do desenvolvimento dessa prática social - desenvolvimento no sentido de aumento da complexificação e não de constante melhoria -, ocorre o desenvolvimento do conhecimento, esse também passa a ser mais complexo o que gera a especialização, pois não é possível a um único sujeito conhecer tudo do fazer e do saber. Entretanto, essa complexificação no modo de produção capitalista tem uma especificidade própria, pois é baseada na divisão do trabalho em manual e intelectual. Embora possa parecer uma divisão natural, ela não é, pois provém do processo social no qual o fazer e o saber estão separados "e essa separação é justificada teoricamente e contribui poderosamente para manter a exploração e a dominação de classes" (TONET, 2013a, p. 732).

Sendo assim, a fragmentação do saber se origina na fragmentação da prática social engendrada pelas relações sociais capitalistas e não a partir do isolamento das disciplinas em si mesmas. E esse conhecimento fragmentado é funcional à reprodução do capital, pois "ao impedir uma visão de totalidade do processo social e ao gerar uma compreensão desse mesmo processo apenas em sua aparência" (TONET, 2013a, p. 737) contribui para reproduzir esse tipo 
de sociedade que depende da prática social fragmentada para se desenvolver. Como a interdisciplinaridade não busca as causas da fragmentação do ensino, apenas reconhece esse estado, suas causas negativas, acaba tornando essa fragmentação em algo natural, um problema de como se ensina. Pressupondo que esse problema é meramente epistêmico, para a interdisciplinaridade sua superação também se dará nesse plano.

Assim, superação qualitativa da fragmentação do saber para chegar em um conhecimento qualitativamente menos fragmentado, necessariamente passa pela superação das relações sociais que fragmentam a prática social que dá origem a esse conhecimento fragmentado. É preciso, portanto, uma transformação radical da sociedade, buscando a superação da divisão entre trabalho manual e intelectual e a superação da divisão em classes sociais, tornando possível deixar de existir a fragmentação do saber que existe atualmente uma sociedade baseada em uma totalidade humana engendrará um conhecimento baseado nessa totalidade.

Entretanto, segundo Tonet (2013a), essa fragmentação, tanto da prática quanto do ensino, não é absoluta. De acordo com o autor, utilizando as contradições existentes no modo de produção capitalista, é possível produzir um conhecimento baseado em uma totalidade. Esse tipo de saber não só é possível (com suas devidas limitações em uma sociedade de classes), como é necessário, pois um saber fundamentado em uma totalidade permite entender e, subsequentemente, desmistificar a realidade social do qual foi engendrado, atendendo dessa forma os interesses da classe trabalhadora; já um saber fragmentado atende aos interesses da classe burguesa e sua manutenção como classe dominante.

Para superar a fragmentação do ensino, é preciso, portanto, tratar o conhecimento em sua totalidade e a interdisciplinaridade trata o conhecimento como a união de diversos fragmentos de ciência (tanto na questão das disciplinas, como na questão dos sujeitos - a equipe multidisciplinar), a partir da lógica formal (da conversa entre as diversas disciplinas), sendo que a totalidade não é a soma de todos os fatos ou o conhecimento de todos os fatos, mas sim que cada fato seja tomado dentro da sua totalidade, a partir das relações constitutivas daquele fenômeno (KOSIK, 2011).

Consideramos a interdisciplinaridade uma pseudodesfragmentação do conhecimento e do ensino, pois se mostra no âmbito educacional enquanto soma de conteúdos pontuais que diversas disciplinas compartilham. Seu princípio é o de que isso permitirá que essas diversas ciências se comuniquem; entretanto, ao não entender a relação dialética entre o concreto e a abstrato, entre a realidade e a sua reflexão no pensamento, não entende que a 
totalidade não é simplesmente um conjunto de momentos particulares abstratos que podem ser somados e que, logo, não basta que disciplinas fragmentadas se comuniquem para que se alcance essa totalidade.

Essa pseudodesfragmentação também se mostra no âmbito da equipe multidisciplinar, que, a partir do mesmo princípio, acredita que a totalidade seria encontrada a partir da simples soma dos diferentes conhecimentos dos diversos membros da equipe. Entendemos que a equipe é, sim, indispensável, mas acreditamos que essa será uma equipe de fato somente quando cada sujeito se apropriar da totalidade do conhecimento. Não será a soma abstrata de fragmentos do conhecimento de cada sujeito singular que formará a totalidade do conhecimento necessária para a prática em saúde.

O conhecimento é conhecimento da realidade; e a realidade é movimento e está recheada de contradições. Para entender esse movimento e essas contradições (enquanto contradições reais e não erros do pensamento), é preciso a lógica dialética para entender $a$ totalidade do conhecimento da realidade objetiva. Isso não quer dizer desprezar a análise da lógica formal, suplantá-la, mas sim, superá-la, o que significa alcançar um estágio mais elevado através da sua incorporação. Entretanto, para realmente superar a fragmentação do conhecimento não basta apenas a lógica dialética, mas a superação de uma realidade fragmentada que engendra um conhecimento fragmentado.

\section{CONSIDERAÇÕES FINAIS}

As Diretrizes Curriculares Nacionais para os cursos de Farmácia não se constituíram de forma isolada, mas resultaram da reforma do ensino superior - decorrente de mudanças na estrutura produtiva da sociedade capitalista no final do século XX, devido à constante taxa de lucro média abaixo do limiar necessário para a própria reprodução do capital. Dessas mudanças na produção, decorre a necessidade de uma nova formação de um novo trabalhador, apto a se enquadrar nessa nova etapa do capitalismo.

O farmacêutico, como trabalhador no modo de produção capitalista, também passa a necessitar de uma nova formação, que surge fundamentada no ideário do aprender a aprender, no qual não é valorizado o conhecimento produzido pela humanidade, mas metodologias ativas que permitam ao estudante se adaptar às diversas situações que possam surgir no mercado de trabalho, desde as mudanças de área de trabalho, quanto ao próprio desemprego. Ao mesmo tempo, essas metodologias vêm ao encontro da necessidade de uma formação superficial, que forme um trabalhador mais barato e destinado à operação da tecnologia, essa sim, detentora do 
conhecimento objetivado nela, fazendo com que o discurso da formação do profissional de saúde voltado ao SUS, fique apenas no discurso.

Além disso, diferentemente dos resultados obtidos por Sousa e Bastos (2016), de que a interdisciplinaridade não é efetivada nos cursos de Farmácia pelo simples nãoentendimento do que é essa prática, o não-entendimento da diferença entre generalista e especialista, da formação cartesiana dos docentes, ou a disputa de poder entre as áreas, acreditamos que a interdisciplinaridade não é efetivada porque não existem condições materiais para isso. Vivemos, atualmente, no modo de produção capitalista, uma realidade fragmentada, pela cisão do trabalho em manual e intelectual que gera, consequentemente, um conhecimento também fragmentado, já que o conhecimento é um reflexo no pensamento da realidade objetiva.

É preciso, portanto, mudanças significativas na sociedade, que tornem a realidade qualitativamente menos fragmentada, para que a educação possa realmente formar um farmacêutico enquanto profissional de saúde.

\section{REFERÊNCIAS}

ALMEIDA FILHO, Naomar de. Transdisciplinaridade e o paradigma pós-disciplinar na saúde. Saúde e Sociedade, v. 14, n. 3, pp. 30-50, 2005. Disponível em <www.scielo.br/pdf/sausoc/v14n3/04.pdf>. Acesso em: 09 fev. 2016.

ALVARENGA, Augusta Thereza de; SOMMERMAN, Américo; ALVAREZ, Aparecida Magali de Souza. Congressos internacionais sobre transdisciplinaridade: reflexões sobre emergências e convergências de idéias e ideais na direção de uma nova ciência moderna.

Saúde e Sociedade, v. 14, n. 3, pp. 9-29, 2005. Disponível em <www.scielo.br/pdf/sausoc/v14n3/03.pdf>. Acesso em: 09 fev. 2016.

ALVESON, Mats; SKÖLDBERG, Kaj. Reflexive methodology: new views for qualitative research. 2.ed. London: Sage, 2009.

ANTUNES, Ricardo. Os sentidos do trabalho: ensaio sobre a afirmação e a negação do trabalho. 2.ed. 10.reimpr. rev. e ampl. São Paulo: Boitempo, 2009.

BOFF, Paulo Roberto. Diretrizes e práticas farmacêuticas: entrevista com farmacêutico e professor Paulo Roberto Boff. Pharmácia Brasileira, Brasília, n. 84, dez./jan./fev., pp. 5055, 2011-2012. Disponível em <www.cff.org.br/sistemas/geral/revista/pdf/136/050a055_entrevista_paulo_boff.pdf>. Acesso em 09 fev. 2016.

BRANNEN, Julia. Mixing methods: the entry of qualitative and quantitative approaches into the research. International Journal of Social Research Methodology, v. 8, n. 3, pp. 173184, 2005. Disponível em <http://dx.doi.org/10.1080/13645570500154642>. Acesso em 29 abr. 2014. 
BRASIL. Resolução CNE/CES nº 02, de 19 de fevereiro de 2002. Institui Diretrizes Curriculares Nacionais do Curso de Graduação em Farmácia. Diário Oficial da União, Brasília, DF, 04 mar. 2002. Disponível em: <portal.mec.gov.br/cne/arquivos/pdf/CES022002.pdf>. Acesso em 09 fev. 2016.

BRASIL. Ministério da Educação. Conselho Nacional de Educação. Câmara de Educação Superior. Resolução n 06, de 19 de outubro de 2017. Institui as Diretrizes Curriculares Nacionais do Curso de Graduação em Farmácia e dá outras providências. Diário Oficial da União, Brasília, DF, 20 out. 2017.

BREYNER, Antonio Juliano. Construção do curso de farmácia no Brasil: introdução a uma proposta para o currículo. Londrina: Edições Humanidades, 2006.

DENZIN, Norman K. Moments, mixed methods, and paradigma dialogs. Qualitative Inquiry, v. 16, n. 6, pp. 419-427, 2010. Disponível em <www.onlinecef.net/file.php/1/CEF_Resources/Research\%20\%20Method/MomentM_Mixed _Methods_and_Paradigm_Dialogs_-_Denzin_2010_.pdf>. Acesso em 16 jun. 2014.

DUARTE, Newton. Vigotski e o “aprender a aprender ”: crítica às apropriações neoliberais e pós-modernas da teoria vigotskiana. 4.ed. Campinas: Autores Associados, 2006.

FERREIRA, Ricardo F.; CALVOSO, Genilda; GONZALES, Carlos B. Lopes. Caminhos da pesquisa e a contemporaneidade. Psicologia: Reflexão e Crítica, v. 15, n. 2, pp. 243-250, 2002.

GUBA, Egon G.; LINCOLN, Yvonna S. Competing paradigms in qualitative research. In: DENZIN, Norman K.; LINCOLN, Yvonna S. (Eds.). Handbook of qualitative research. Thousand Oaks: Sage, 1994, pp. 105-117.

HOBSBAWM, Eric. Era dos extremos: o breve século XX (1914-1991). 2.ed. 45.reimpr. São Paulo: Companhia das Letras, 2011.

ILYENKOV, Evald Vasilievich. Dialectical logic: essays on its history and theory. Delhi: Aakar Books, 2010.

KLIMAN, Andrew. The failure of capitalist production: underlying causes of the Great Recession. London: Pluto Press, 2012.

KOSIK, Karel. A dialética do concreto. 2.ed. 9.reimpr. Rio de Janeiro: Paz e Terra, 2011.

MARX, Karl. O capital: crítica da economia política. Livro I: o processo de produção do capital. São Paulo: Boitempo, 2013.

MARX, Karl; ENGELS, Friedrich. A ideologia alemã: crítica da mais recente filosofia alemã em seus representantes Feuerbach, B. Bauer e Stirner, e do socialismo alemão em seus diferentes profetas (1845-1846). São Paulo: Boitempo, 2009. 
MONTEGUTI, Bruna Ruzza; DIEHL, Eliana Elisabeth. O ensino de farmácia no sul do brasil: preparando farmacêuticos para o sistema único de saúde? Trab. educ. saúde, Rio de Janeiro, v. 14, n. 1, pp. 77-95, 2016. Disponível em <http://dx.doi.org/10.1590/1981-7746sol00008>. Acesso em 09 fev. 2016.

ROSSLER, João Henrique. Sedução e alienação no discurso construtivista. Campinas: Autores Associados, 2006.

RUTO-KORIR, Rose; LUBBE, Carien. Locating the doctoral study in the "paradigm skirmishes': challenges and prospects for adopting a paradigm cradle. Perspectives in Education, v. 28, n. 3, pp. 99-109, 2010. Disponível em $<$ http://repository.up.ac.za/bitstream/handle/2263/15235/RutoKorir_Locating(2010).pdf?sequ sequ=1>. Acesso em 09 jun. 2014.

SAMPIERI, Roberto H.; CALLADO, Carlos F.; LUCIO, María del Pilar B. Metodologia da pesquisa. 5.ed. Porto Alegre: Penso, 2013.

SAVIANI, Dermeval. Pedagogia histórico-crítica: primeiras aproximações. 10.ed. rev. Campinas: Autores Associados, 2008.

SAUTU, Ruth; BONIOLO, Paula; DALLE, Pablo; ELBERT, Rodolfo. Manual de metodología: construcción del marco teórico, formulación de los objetivos y elección de la metodología. Buenos Aires: CLACSO, 2005.

SOUSA, Iane Franceschet de; BASTOS, Paulo Roberto Haidamus de Oliveira. Interdisciplinaridade e formação na área de farmácia. Trab. educ. saúde, Rio de Janeiro, v. 14, n. 1, pp. 97-117, 2016. Disponível em <http://dx.doi.org/10.1590/1981-7746-sip00092>. Acesso em 09 fev. 2016.

TONET, Ivo. Interdisciplinaridade, formação e emancipação humana. Serv. Soc. Soc., n. 116, pp. 725-742, 2013a. Disponível em <www.scielo.br/pdf/sssoc/n116/08.pdf>. Acesso em: 09 fev. 2016. 